\title{
Comparison of the behavioral effects of exercise and high fat diet on cognitive function in adolescent rats
}

\author{
Jae-Min Lee', Jong-Min Park², Min Kyung Song ${ }^{2}$, Yoon Ju Kim², Youn-Jung Kim ${ }^{2 *}$ \\ 'Department of Physiology, College of Medicine, Kyung Hee University, Seoul, Korea \\ ${ }^{2}$ Department of Basic Nursing Science, College of Nursing Science, Kyung Hee University, Seoul, Korea
}

Adolescence is a critical period for neurodevelopment, neuronal plasticity, and cognitive function. Experiences of adolescence can be exerted positive and negative effects on brain development. Physical exercise has a positive effect on brain function, which is characterized by improving memory function and increased neural plasticity. High fat diet (HFD)-induced obesity has a negative effect on brain function, which is characterized by insulin resistance and neuroinflammation and reduced microvessel constructure. Although the positive effect of exercise and negative effect of obesity on cognitive function have been documented, it has not been well whether comparison of the effects of exercise and obesity on cognitive function in adolescent rats. In the present study, we evaluated the behavioral changes related to cognitive function induced by exercise and obesity in adolescent rats. Male Wistar rats were randomly divided into three groups: the control group
(CON), the exercise group (Ex), the high fat diet group (HFD). The HFD containing fat $60 \%$ was freely provided. The present results showed that spatial learning ability and short-term memory did not show significant effect exercise as compared to the control group. The present results showed that spatial learning ability and short-term memory was significantly decreased HFD-induced obesity group as compared to the control group. These results suggest that positive effect of physical exercise in adolescence rats may be exerted no significant effect on cognitive function. But, negative effect of HFD-induced obesity might induce cognitive impairment. HFD-induced obesity in adolescent rats may be used as an animal model of neurodevelopmental disorders.

Keywords: Exercise, High fat diet, Cognitive impairment, Morris water maze test, Step-down avoidance test

\section{INTRODUCTION}

Adolescence is a time of dramatic change and rapid growth in the life (Johnson et al., 2009; Spear, 2002). These growth and development from adolescence drive many aspects of biological processes, which can be characterized by behavioral, hormonal and neurochemical changes (López-Arnau et al., 2015; Steinberg, 2005). Experiences of adolescence can be exerted positive and negative effects on brain development. Evidence from animal studies suggests that environmental factors in adolescent rats can influences cognitive function (Comeau et al., 2015; Shao et al., 2013).

Physical exercise has a positive effect on brain function, which is characterized by improving memory function and increased

neural plasticity (Cotman and Engesser-Cesar, 2002; Jin et al., 2008). Many previous studies have shown that physical exercise may contribute to cognitive improvement in the aging brain by preserving adult neurogenesis (Winocur et al., 2014; Yau et al., 2014). Enhanced of neurogenesis is implicated in the improvement of memory function and enhances neuronal plasticity (Lledo et al., 2006). Exercise is known to improve cognitive function and ameliorates neurological impairment following various brain injuries such as cerebral ischemia, Alzheimer, and Parkinson diseases (Lee et al., 2014; Seo et al., 2014; Yoon et al., 2007). Several animal studies have provided strong evidence to suggest that physical exercise-induced cognitive improvement has been correlated with a protection of age-related hippocampal damage.

*Corresponding author: Youn-Jung Kim (iD http://orcid.org/0000-0003-4991-0825 Department of Basic Nursing Science, College of Nursing Science, Kyung Hee University, 26 Kyungheedae-ro, Dongdaemun-gu, Seoul 02447, Korea Tel: +82-2-961-0311, Fax: +82-2-961-9398. E-mail: yj129@khu.ac.kr Received: November 2, 2016 / Accepted: November 28, 2016
This is an Open Access article distributed under the terms of the Creative Commons Attribution Non-Commercial License (http://creativecommons.org/licenses/by-nc/4.0/) which permits unrestricted non-commercial use, distribution, and reproduction in any medium, provided the original work is properly cited. 
High fat diet (HFD)-induced obesity has a negative effect on brain function, which is characterized by insulin resistance and adipose tissue inflammation and reduced memory ability (Cho et al., 2016; Kim et al., 2016; Norris et al., 2016). It has been associated with increased risk of several diseases including type 2 diabetes, cardiovascular disease, prostate cancer, dementia, and Alzheimer disease (Balistreri et al., 2010). Many previous studies have shown that overweight or obesity is associated with decrease of cognitive function (Baxendale et al., 2015; Lennox et al., 2015). Cognitive performance in adult patients is affected by insulin resistance, steady-state plasma glucose levels, and body mass index (Fukushima et al., 2016). HFD-induced obesity impairs structure and functions of hippocampus in mice (Medic et al., 2016; Park et al., 2010).

Although the positive effect of exercise and negative effect of obesity on cognitive function have been documented, it has not been well whether comparison of both effects of exercise and obesity on cognitive function in adolescent rats. In the present study, we evaluated the behavioral changes related to cognitive function induced by exercise and obesity in adolescent rats.

\section{MATERIALS AND METHODS}

\section{Animals and housing conditions}

Male Wistar rats ( $80 \pm 10 \mathrm{~g}, 4$ weeks old) were used in this study. All animal experimental procedures conformed to the regulations stipulated by the National Institutes of Health and the guidelines of the Korean Academy of Medical Science. This study was approved by the Kyung Hee University Institutional Animal Care and Use Committee (Seoul, Korea) (KHUASP [SE]-15-082). The mice were housed under controlled temperature $\left(20^{\circ} \mathrm{C} \pm 2^{\circ} \mathrm{C}\right)$ and lighting (07:00 a.m. to 19:00 p.m.) conditions with food and water available ad libitum. The rats were randomly divided into three groups: the control group (CON, $n=10)$, the exercise group (Ex, $n=16$ ), the high fat diet group (HFD, $n=16)$. The HFD containing fat $60 \%$ was freely provided.

\section{Treadmill exercise protocol}

The rats in the exercise group were made to run on a treadmill for 30 min once a day for 8 weeks starting 4 weeks after birth, according to the previously described method (Kim et al., 2004). The treadmill exercise load consisted of running at $2 \mathrm{~m} / \mathrm{min}$ for the first of $5 \mathrm{~min}$, at $3 \mathrm{~m} / \mathrm{min}$ for the next $5 \mathrm{~min}$, and then at 5 $\mathrm{m} / \mathrm{min}$ for the last $20 \mathrm{~min}$ at 0 degree of inclination. The rats in the CON and HFD groups were left in treadmill without run- ning for the same period as the exercise group.

\section{Morris water maze test}

Morris water maze test In order to evaluate the spatial learning ability in rats, the latency in the Morris water maze test was determined, as the previously described method (Heo et al., 2014). The Morris water maze consisted of a circular pool (painted white, 200 -cm diameter, 35 -cm height), filled with water $\left(22^{\circ} \mathrm{C} \pm 2^{\circ} \mathrm{C}\right)$ made opaque addition $1 \mathrm{~kg}$ of skim milk powder. A platform (15$\mathrm{cm}$ diameter, $35-\mathrm{cm}$ height) submersed $2 \mathrm{~cm}$ below the water surface in one of four quadrants in the pool. There were several visual cues on the walls of the room. A video-recorder was hanged from the ceiling and was connected to a tracking device (S-MART: Pan-Lab, Barcelona, Spain). The animals were subjected to three trials per session. For each trial, the rat was placed in the water, facing the wall of the tank, in one of the three start locations. The rat was allowed to search for the platform for $60 \mathrm{sec}$. If the rat found the platform, remaining on the platform for $10 \mathrm{sec}$ was permitted. If the rat did not find the platform within $60 \mathrm{sec}$, the rat was guided and allowed to remain on the platform for $10 \mathrm{sec}$. The latency times to find the submerged platform were recorded. The animals were tested in this way for 4 days.

\section{Step-down avoidance test}

In order to evaluate short-term memory in the rats, the latency in the step-down avoidance test was determined, as the previously described method (Shin et al., 2016). The rats were trained in a step-down avoidance test on the 7 weeks. The rats were positioned on a $7 \times 25-\mathrm{cm}$ platform with a height of $2.5 \mathrm{~cm}$, and then allowed to rest on the platform for $2 \mathrm{~min}$. The platform faced a $42 \times$ $25-\mathrm{cm}$ grid of parallel $0.1-\mathrm{cm}$ caliber stainless steel bars, which were spaced $1 \mathrm{~cm}$ apart. In the training sessions, the animals received 0.3-mA scramble foot shock for 2 sec immediately upon stepping down. After $24 \mathrm{hr}$, retention time was assessed. The interval of rats stepping down and placing all four paws on the grid was defined as the latency time. The latency over $300 \mathrm{sec}$ was counted as $300 \mathrm{sec}$.

\section{Statistical analysis}

The results are expressed as mean \pm standard error of the mean. IBM SPSS Statistics ver. 21.0 (IBM Co., Armonk, NY, USA) was used for statistical analysis. Statistical analysis was performed using one-way analysis of variance followed by Duncan post hoc test. Differences between groups were considered significant at $P<0.05$. 


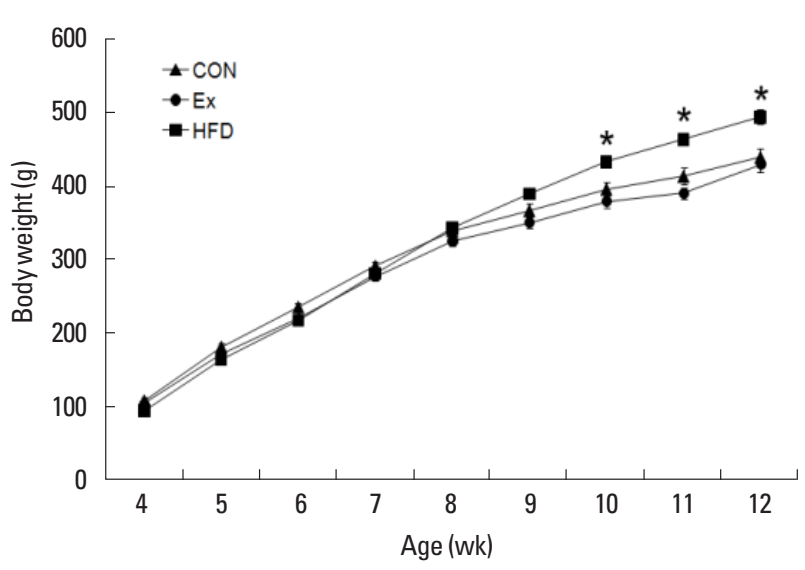

Fig. 1. Effect of exercise and obesity on body weight. CON, control group, Ex, treadmill exercise group, HFD, high-fat diet group. Data are expressed as the mean \pm standard error of the mean. ${ }^{*} P<0.05$ compared to the CON group.

\section{RESULTS}

\section{Effects of exercise and obesity on body weight}

The body weight was significantly increased to $434.75 \pm 7.57 \mathrm{~g}$ in HFD group after 6 weeks of the high fat diet as compared to $397.43 \pm 9.78 \mathrm{~g}$ in the CON group after a regular diet. The body weight was significantly increased to $465.50 \pm 8.67 \mathrm{~g}$ in the HFD group after 7 weeks of the high fat diet as compared to $415.14 \pm$ $10.97 \mathrm{~g}$ in CON group after a regular diet. The body weight was significantly increased to $496.50 \pm 9.54 \mathrm{~g}$ in the HFD group after 8 weeks of the high fat diet as compared to $441.14 \pm 11.87 \mathrm{~g}$ in the $\mathrm{CON}$ group after a regular diet $(P<0.05)$. In contrast, the Ex group did not show significant effect following treadmill exercise as compared to the CON group (Fig. 1).

\section{Effects of exercise and obesity on spatial learning ability in the Morris water maze test}

Spatial learning ability was measured using the Morris water maze test (Fig. 2). The escape latency time (in seconds) is demonstrated for the 4 days of reference memory testing. The escape latency $(\mathrm{sec})$ of the 4-day trial was significantly increased to $42.56 \pm 2.63 \mathrm{sec}$ in the HFD group as compared to $28.13 \pm 3.86$ sec in the CON group $(P<0.05)$. In contrast, the Ex group did not show significant effect following treadmill exercise as compared to the CON group.

\section{Effects of exercise and obesity on short-term memory in step-down avoidance test}

Short-term memory was measured using the step-down avoid-
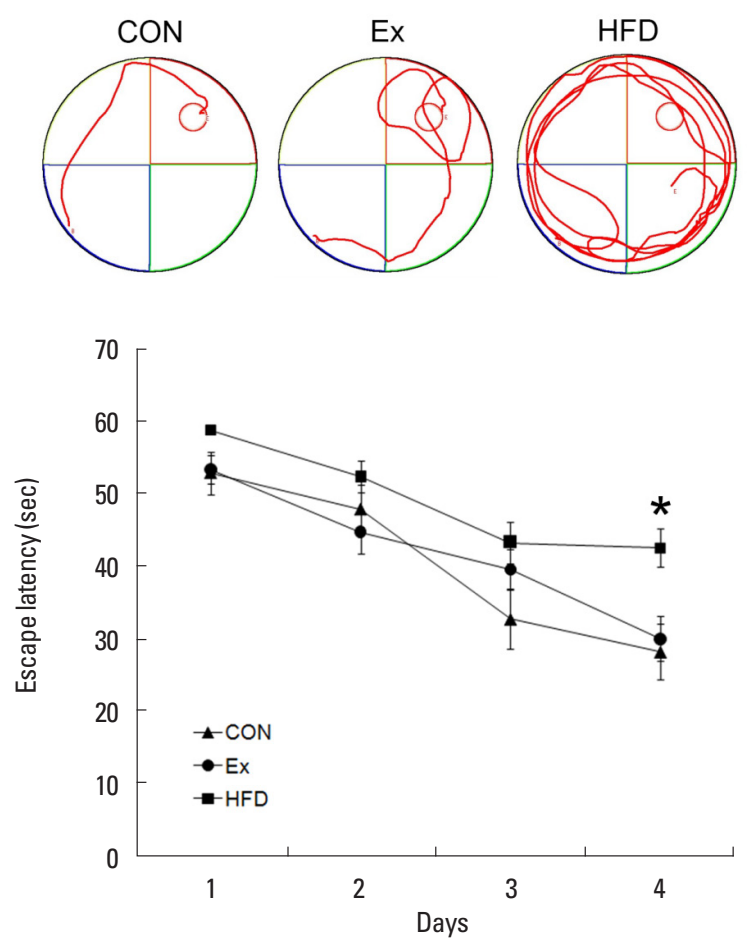

Fig. 2. Effect of exercise and obesity on special learning and memory in the Morris water maze test. CON, control group, Ex, treadmill exercise group, HFD, high-fat diet group. Data are expressed as the mean \pm standard error of the mean). ${ }^{*} P<0.05$ compared to the CON group.

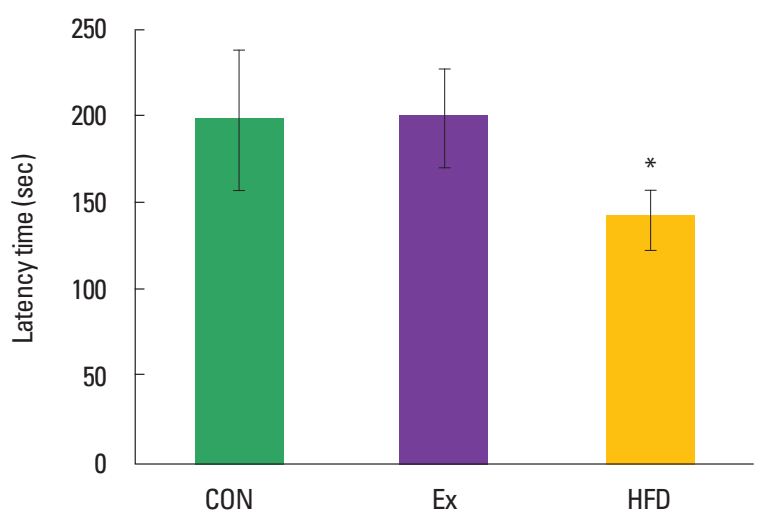

Fig. 3. Effect of exercise and obesity on special learning and memory in the step-down avoidance test. CON, control group, Ex, treadmill exercise group, HFD, high-fat diet group. Data are expressed as the mean \pm standard error of the mean. ${ }^{*} P<0.05$ compared to the $\mathrm{CON}$ group.

ance test (Fig. 3). The latency time (sec) was significantly decreased to $87.63 \pm 16.47 \mathrm{sec}$ in the HFD group as compared to $198.30 \pm 38.06 \mathrm{sec}$ in the $\mathrm{CON}$ group $(P<0.05)$. In contrast, the Ex group $(199.30 \pm 27.48 \mathrm{sec})$ did not show significant effect following treadmill exercise as compared to the $\mathrm{CON}$ group. 


\section{DISCUSSION}

Physical exercise improves cognitive function, hippocampal neurogenesis, neural plasticity induce by neurotrophic factors (Altmann et al., 2016; Baek, 2016; Sim et al., 2004). Most prior studies have demonstrated the effects of exercise on cognitive impairment induced by several diseases (Baek, 2016; Ma et al., 2017). HFD-induced obesity model was used to indicate cognitive impairment, depression, and anxiety (Abildgaard et al., 2011; Kaczmarczyk et al., 2013). In the present study, we evaluated the effects of exercise and obesity on cognitive function in adolescent rats. As previously mentioned, adolescence is a critical period for stabilization of neural circuit, neuronal plasticity, and intellectually and emotionally improvement. In present study demonstrated the effects of exercise and obesity on cognitive function in adolescent rats.

A recent study showed that treadmill exercise in normal adolescent miceimproves short-term memory in the Y-maze test. Also, brain-derived neurotrophic factor (BDNF) and tyrosine kinase $\mathrm{B}$ (TrkB) expression and cell proliferation in normal adolescent mice were increased after treadmill exercise for 12 weeks (Kim et al., 2016). Increased expression of hippocampal BDNF and enhanced cell proliferation caused by treadmill exercise might facilitate neuroplasticity in mice (Ma et al., 2017; Seo et al., 2014). The present results showed that treadmill exercise was similar level of control group on spatial learning ability and short-term memory. Consistent with our study, the several reports have demonstrated that the sham+Ex group exerted no significant effect on the number of error choice in the radial 8-arm maze test as compared to the sham group. However, treadmill exercise enhanced BDNF and TrkB expressions in the hippocampus of rats (Sim, 2014). Many studies have shown that treadmill exercise in young normal animals exerted no significant effect on spatial learning and memory and short-term memory in the radial 8-arm maze and step-down avoidance tests (Heo et al., 2014; Kim et al., 2010). In the light of these results demonstrate that treadmill exercise in normal young animals may be exerted no significant effect on cognitive function as compared to the control group.

The HFD-induced obesity is considered to reduce neuronal plasticity and cognitive function in the brain (Murray et al., 2009; Woo et al., 2013). HFD is associated with reduced BDNF and reduced performance on an active avoidance test (Noble et al., 2014). A recent study showed that cognitive function was impaired in the HFD-induced obese mice (Kim et al., 2016). However, HFD initiated in adolescent but not adult mice impaired memory ability in the water maze test (Klein et al., 2016). The present results showed that spatial learning ability and short-term memory was significantly decreased HFD-induced obesity group as compared to the control group. Consistent with our study, the majority of reports have demonstrated that HFD-induced obese mice were reduced the number of neurons in the hippocampus. These results indicate that HFD-induced obesity in normal animals can be caused by cognitive impairment.

These results suggest that positive effect of physical exercise in adolescence rats may be exerted no significant effect on cognitive function. But, negative effect of HFD-induced obesity might induce cognitive impairment. HFD-induced obesity in adolescent rats may be used as an animal model of neurodevelopmental disorders.

\section{CONFLICT OF INTEREST}

No potential conflict of interest relevant to this article was reported.

\section{ACKNOWLEDGMENTS}

This work was supported by National Research Foundation of Korea (NRF) funded by the Ministry of Education, Science and Technology (NRF-2014R1A2A2A01007909).

\section{REFERENCES}

Abildgaard A, Solskov L, Volke V, Harvey BH, Lund S, Wegener G. A high-fat diet exacerbates depressive-like behavior in the Flinders Sensitive Line (FSL) rat, a genetic model of depression. Psychoneuroendocrinology 2011;36:623-633.

Altmann LJ, Stegemöller E, Hazamy AA, Wilson JP, Bowers D, Okun MS, Hass CJ. Aerobic exercise improves mood, cognition, and language function in parkinson's disease: results of a controlled study. J Int Neuropsychol Soc 2016;22:878-889.

Baek SS. Role of exercise on the brain. J Exerc Rehabil 2016;12:380-385.

Balistreri CR, Caruso C, Candore G. The role of adipose tissue and adipokines in obesity-related inflammatory diseases. Mediators Inflamm 2010;2010:802078.

Baxendale S, McGrath K, Donnachie E, Wintle S, Thompson P, Heaney D. The role of obesity in cognitive dysfunction in people with epilepsy. Epilepsy Behav 2015;45:187-190.

Cho KW, Zamarron BF, Muir LA, Singer K, Porsche CE, DelProposto JB, Geletka L, Meyer KA, O'Rourke RW, Lumeng CN. Adipose tissue 
dendritic cells are independent contributors to obesity-induced inflammation and insulin resistance. J Immunol 2016;197:3650-3661.

Comeau WL, Lee K, Anderson K, Weinberg J. Prenatal alcohol exposure and adolescent stress increase sensitivity to stress and gonadal hormone influences on cognition in adult female rats. Physiol Behav 2015;148:157-165.

Cotman CW, Engesser-Cesar C. Exercise enhances and protects brain function. Exerc Sport Sci Rev 2002;30:75-79.

Fukushima Y, Kurose S, Shinno H, Cao Thu H, Takao N, Tsutsumi H, Kimura Y. Importance of lean muscle maintenance to improve insulin resistance by body weight reduction in female patients with obesity. Diabetes Metab J 2016;40:147-153.

Heo YM, Shin MS, Kim SH, Kim TW, Baek SB, Baek SS. Treadmill exercise ameliorates disturbance of spatial learning ability in scopolamine-induced amnesia rats. J Exerc Rehabil 2014;10:155-161.

Jin J, Jing H, Choi G, Oh MS, Ryu JH, Jeong JW, Huh Y, Park C. Voluntary exercise increases the new cell formation in the hippocampus of ovariectomized mice. Neurosci Lett 2008;439:260-263.

Johnson SB, Blum RW, Giedd JN. Adolescent maturity and the brain: the promise and pitfalls of neuroscience research in adolescent health policy. J Adolesc Health 2009;45:216-221.

Kaczmarczyk MM, Machaj AS, Chiu GS, Lawson MA, Gainey SJ, York JM, Meling DD, Martin SA, Kwakwa KA, Newman AF, Woods JA, Kelley KW, Wang Y, Miller MJ, Freund GG. Methylphenidate prevents high-fat diet (HFD)-induced learning/memory impairment in juvenile mice. Psychoneuroendocrinology 2013;38:1553-1564.

Kim SE, Ko IG, Kim BK, Shin MS, Cho S, Kim CJ, Kim SH, Baek SS, Lee EK, Jee YS. Treadmill exercise prevents aging-induced failure of memory through an increase in neurogenesis and suppression of apoptosis in rat hippocampus. Exp Gerontol 2010;45:357-365.

Kim TW, Choi HH, Chung YR. Treadmill exercise alleviates impairment of cognitive function by enhancing hippocampal neuroplasticity in the high-fat diet-induced obese mice. J Exerc Rehabil 2016;12:156-162.

Kim YP, Kim H, Shin MS, Chang HK, Jang MH, Shin MC, Lee SJ, Lee $\mathrm{HH}$, Yoon JH, Jeong IG, Kim CJ. Age-dependence of the effect of treadmill exercise on cell proliferation in the dentate gyrus of rats. Neurosci Lett 2004;355:152-154.

Klein C, Jonas W, Iggena D, Empl L, Rivalan M, Wiedmer P, Spranger J, Hellweg R, Winter Y, Steiner B. Exercise prevents high-fat diet-induced impairment of flexible memory expression in the water maze and modulates adult hippocampal neurogenesis in mice. Neurobiol Learn Mem 2016;131:26-35.

Lee JM, Shin MS, Ji ES, Kim TW, Cho HS, Kim CJ, Jang MS, Kim TW, Kim BK, Kim DH. Treadmill exercise improves motor coordination through ameliorating Purkinje cell loss in amyloid beta23-35-induced
Alzheimer's disease rats. J Exerc Rehabil 2014;10:258-264.

Lennox R, Moffett RC, Porter DW, Irwin N, Gault VA, Flatt PR. Effects of glucose-dependent insulinotropic polypeptide receptor knockout and a high-fat diet on cognitive function and hippocampal gene expression in mice. Mol Med Rep 2015;12:1544-1548.

Lledo PM, Alonso M, Grubb MS. Adult neurogenesis and functional plasticity in neuronal circuits. Nat Rev Neurosci 2006;7:179-193.

López-Arnau R, Martínez-Clemente J, Rodrigo T, Pubill D, Camarasa J, Escubedo E. Neuronal changes and oxidative stress in adolescent rats after repeated exposure to mephedrone. Toxicol Appl Pharmacol 2015;286:27-35.

Ma CL, Ma XT, Wang JJ, Liu H, Chen YF, Yang Y. Physical exercise induces hippocampal neurogenesis and prevents cognitive decline. Behav Brain Res 2017;317:332-339.

Medic N, Ziauddeen H, Ersche KD, Farooqi IS, Bullmore ET, Nathan PJ, Ronan L, Fletcher PC. Increased body mass index is associated with specific regional alterations in brain structure. Int J Obes (Lond) 2016; 40:1177-1182.

Murray AJ, Knight NS, Cochlin LE, McAleese S, Deacon RM, Rawlins JN, Clarke K. Deterioration of physical performance and cognitive function in rats with short-term high-fat feeding. FASEB J 2009;23:43534360 .

Noble EE, Mavanji V, Little MR, Billington CJ, Kotz CM, Wang C. Exercise reduces diet-induced cognitive decline and increases hippocampal brain-derived neurotrophic factor in CA3 neurons. Neurobiol Learn Mem 2014;114:40-50.

Norris GH, Porter CM, Jiang C, Millar CL, Blesso CN. Dietary sphingomyelin attenuates hepatic steatosis and adipose tissue inflammation in high-fat-diet-induced obese mice. J Nutr Biochem 2016;40:36-43.

Park HR, Park M, Choi J, Park KY, Chung HY, Lee J. A high-fat diet impairs neurogenesis: involvement of lipid peroxidation and brain-derived neurotrophic factor. Neurosci Lett 2010;482:235-239.

Seo TB, Kim TW, Shin MS, Ji ES, Cho HS, Lee JM, Kim TW, Kim CJ. Aerobic exercise alleviates ischemia-induced memory impairment by enhancing cell proliferation and suppressing neuronal apoptosis in hippocampus. Int Neurourol J 2014;18:187-197.

Shao F, Han X, Shao S, Wang W. Adolescent social isolation influences cognitive function in adult rats. Neural Regen Res 2013;8:1025-1030.

Shin MS, Park HK, Kim TW, Ji ES, Lee JM, Choi HS, Kim MY, Kim YP. Neuroprotective effects of bone marrow stromal cell transplantation in combination with treadmill exercise following traumatic brain injury. Int Neurourol J 2016;20(Suppl 1):S49-56.

Sim YJ. Treadmill exercise alleviates impairment of spatial learning ability through enhancing cell proliferation in the streptozotocin-induced Alzheimer's disease rats. J Exerc Rehabil 2014;10:81-88. 
Sim YJ, Kim SS, Kim JY, Shin MS, Kim CJ. Treadmill exercise improves short-term memory by suppressing ischemia-induced apoptosis of neuronal cells in gerbils. Neurosci Lett 2004;372:256-261.

Spear BA. Adolescent growth and development. J Am Diet Assoc 2002; 102(3 Suppl):S23-29.

Steinberg L. Cognitive and affective development in adolescence. Trends Cogn Sci 2005;9:69-74.

Winocur G, Wojtowicz JM, Huang J, Tannock IF. Physical exercise prevents suppression of hippocampal neurogenesis and reduces cognitive impairment in chemotherapy-treated rats. Psychopharmacology (Berl) 2014;231:2311-2320.
Woo J, Shin KO, Park SY, Jang KS, Kang S. Effects of exercise and diet change on cognition function and synaptic plasticity in high fat diet induced obese rats. Lipids Health Dis 2013;12:144.

Yau SY, Gil-Mohapel J, Christie BR, So KF. Physical exercise-induced adult neurogenesis: a good strategy to prevent cognitive decline in neurodegenerative diseases? Biomed Res Int 2014;2014:403120.

Yoon MC, Shin MS, Kim TS, Kim BK, Ko IG, Sung YH, Kim SE, Lee HH, Kim YP, Kim CJ. Treadmill exercise suppresses nigrostriatal dopaminergic neuronal loss in 6-hydroxydopamine-induced Parkinson's rats. Neurosci Lett 2007;423:12-17. 